\title{
Ultrasonic 3D Reconstruction and Measurement of Lacrimal Sac in Normal Adult Chinese Population
}

\author{
Reconstrucción 3D con Ultrasonido y Mediciones del Saco \\ Lagrimal en una Población China de Adultos Normales
}

Hai Tao*; Xiaohang Liu*; Xi Mei*;Cui Han*; Peng Wang* \& Fang Bai*

TAO, H.; LIU, X.; MEI, X.; HAN, C.; WANG, P. \& BAI, F. Ultrasonic 3D reconstruction and measurement of lacrimal sac in normal adult Chinese population. Int. J. Morphol., 34(4):1357-1361, 2016.

SUMMARY: To apply the ultrasonic 3D reconstruction method to measure the anatomic image data of lacrimal sac in the normal adult Chinese population, providing imaging anatomical basis for the clinical diagnosis and treatment of lacrimal duct diseases. 80 volunteers without lacrimal duct diseases were enrolled. The GE Voluson E8 ultrasonic diagnostic apparatus was used, with gynecological intracavitary probe (frequency: $5 \sim 12 \mathrm{MHz}$ ) for the examination and measurement. Each datum was repeated three times for the average value.Among the 80 eyes, the lacrimal sacs of 74 eyes exhibited the clear imaging, with the imaging rate as $92.5 \%$. the vertical diameter of lacrimal sac cavity (LSC): $13.3 \pm 2.2 \mathrm{~mm}$; anteroposterior diameter: $6.0 \pm 1.1 \mathrm{~mm}$; trans diameter: $4.9 \pm 0.9 \mathrm{~mm}$; the vertical distance from the sac cavity top to the skin surface: $6.3 \pm 0.12 \mathrm{~mm}$, the vertical distance from the sac cavity bottom to the skin surface: $6.5 \pm 0.11 \mathrm{~mm}$; the distance from the angular artery to the medial canthus: $7.8 \pm 0.05 \mathrm{~mm}$; the vertical distance from the angular artery to the skin surface: $7.7 \pm 0.08 \mathrm{~mm}$. The lacrimal sac and angular artery in the adults could be shown clearly in ultrasonic 3D reconstruction, the accumulated anatomical parameters could provide the instructive meanings towards the clinical diagnosis and treatment of lacrimal diseases.

KEY WORDS: Lacrimal sac; Ultrasonic 3D reconstruction; Imaging anatomy.

\section{INTRODUCTION}

Lacrimal disease is the common and frequentlyoccurring disease of ophthalmology (Tao et al., 2013; Hodgson et al., 2014; Lee et al., 2014), including the inflammation, trauma, calculus, polyps, tumors and congenital abnormalities of lacrimal duct, the lacrimal duct obstruction was considered as the main pathological feature, and the main clinical manifest was the epiphora (Berlucchi et al., 2003; Agrawal et al., 2013; Tao et al., 2014). Looking for a non-invasive imaging method to accurately determine the location and size of lacrimal sac, as well as the anatomical relationships with the surrounding tissues, would provide the instructive meanings towards the diagnosis and treatment of lacrimal diseases. The ultrasonic 3D imaging (U3DI) is a newly emerging diagnostic technology, which could help the doctors to deepen the understanding of anatomic structures (Lembet et al., 2008; Bojikian et al., 2013; Byun et al., 2013). Prager et al., (2010) described the principles of U3DI, ultrasonic 3D digital beam forming technology, diversified 2D image collection, voxel model-3d image reconstruction, all greatly improved the resolution and quality of ultrasonic images, enrich the information that 2D ultrasound could not realize, and could understand more information of the internal structure from any cutting-angle section, meanwhile, it could provide a much more intuitive and repeatable 3D spatial form. But there is no systematic report domestically and abroad about the ultrasonic 3D imaging anatomical features of adult LSC. In this paper, the lacrimal sacs of 80 eyes of normal adult Chinese population were performed the investigation of $3 \mathrm{D}$ reconstruction imaging characteristics, the in vivo anatomic image data of lacrimal sac and angular artery were measured, and reported as the following.

\section{MATERIAL AND METHOD}

80 Subjects, volunteers of normal Chinese adults, without lacrimal duct diseases or lacrimation-related diseases, were enrolled, including 40 males and 40 females, aged 18 to

* Lacrimal Center, Department of Ophthalmology, Armed Police General Hospital of China, No 69 Yongding Road Haidian Dist. 100039 Beijing, China. 
82 years old, with the mean age as 40.5 years old. This study was conducted in accordance with the declaration of Helsinki. This study was conducted with approval from the Ethics Committee of Armed Police General Hospital of China. Written informed consent was obtained from all participants. The inclusion criteria: 1.- Without lacrimation, dry eye and other ocular discomforts; $2 .-$ The tear secretion was normal; 3.- The slit lamp examination exhibited no abnormality of punctal shape and position, conjunctivochalasis, hypertrophy of lacrimal caruncle and anterior segment inflammation, etc.; 4.- Without abnormality of eyelid medial canthus and eyelidrelated diseases; 5.- Without previous surgery and trauma history in the ocular region, head and face. Except for children, patients with severe systemic disease and those who did not want to participate in the research project, the included volunteers should meet all of the above standards.

Examination methods. 80 volunteers with normal lacrimal duct participated in the study, the left and right eyes were randomly selected, with a total of 80 eyes. The volunteer was in the supine position, with the eyeball gazing at the above location then closed the eyes, a water bladder filled with 60 $\mathrm{ml}$ distilled water was put on the eye region, and the ultrasonic probe was placed just above the area of lacrimal sac, with the indicating line perpendicular to the eyelid . the GE Voluson E8 Ultrasound Scanner (GE Healthcare, USA) was used for the check, when the complete eyeball echo was obtained, the probe should be moved slowly towards the medial canthus, during which period, the probe scanning tangent was kept vertical with the eyelid, when the ultrasonic probe found the lacrimal sac, made it stay in the center of screen, and adjusted the depth, pulse repetition frequency, focus area and sampling volume based on individual circumstances so that it could cover the full width of LSC; labeled the probe position, and pressed the 3D button, kept the probe stable, and pressed the freezing button for the automatic acquisition of 3D volumetric ultrasonic data, the data were stored in the hard disk for the later processing. The data post-processing was performed in the ultrasonic diagnostic apparatus, the same datum was detected three times for the average, all measurements were completed by the same operator.

Blood flow regulation. The blood flow and energy Doppler conditions should select the suitable parameters, including the transmitting frequency, dynamic range, filtering, depth, gain, speed meter and others, the wall filtering should be set as the minimum, so that the blood flow signal could not spill.

2D ultrasound. Main observation outcomes: location of LSC, range, relationships with the surrounding tissues, internal echo and echo type, angular artery imaging, vertical distances from the angular artery to the medial canthus and skin, trans diameter of angular artery.
Ultrasonic 3D reconstruction (U3DR). The vertical diameter of LSC was measured under the eye-closing conditions (LSC top to the junction of LSC and nasolacrimal duct), anteroposterior diameter (the widest distance between the front and rear sidewalls of LSC), trans diameter (the widest distance between the right and left sidewalls of LSC); the vertical distances from LSC top and bottom to the medial canthus and skin were measured.

Statistical analysis. Microsoft Excel 2007 (Microsoft, USA) software was used to build a database and perform the data management, SPSS 17.0 software (IBM, USA) was used for the statistical analysis, the paired samples were performed the mean value comparison by t-test, with $\mathrm{p}<0.05$ considered as the statistical difference, and $p<0.01$ considered as the statistically significant difference. The measurement values were expressed as $\overline{\mathrm{X}} \pm \mathrm{S}_{\mathrm{X}}$.

\section{RESULTS}

Imaging conditions. Among the 80 selected eyes, 74 successfully exhibited the U3DR imaging, with the imaging rate as $92.5 \%$. The images of sac cavity structure of 6 patients ( 2 males and 4 females) were unclear, and thus excluded, the possible reasons might be that 2 males had the higher nasal bone, the orbital cavity was deeper, thus the lacrimal sac was in the fossa of lacrimal sac, occluded by the surrounding bony structures, the other 4 females were over 70 years old, the reason might be because of their older ages, the skins surrounding the lacrimal sac were loose, with much more wrinkles, which increased the ultrasonic sound attenuation, and not conducive to the ultrasound imaging of LSC. Among the 74 successful cases, the U3DR features of normal LSC under the natural and eye-closing states were in Fig. 1-1: the lacrimal sac was approximately oval, with rounded top, became narrow suddenly at the junction of LSC and nasolacrimal duct, and the lacrimal sac anterior wall fused together with the initial section echo, the back wall was clear, exhibiting the line shape, without reflection in the cavity, or with a very small pointlike reflections, the blood flow signals could be seen in the para-hypoechoic areas.

LSC segments and transdiameter of angular artery. The results showed that: there was no statistically significant difference in the vertical diameter, anteroposterior diameter and transdiameter of LSC between the different sexs (Table I); the trans diameter of angular artery: male and female were all $0.7 \pm 0.3 \mathrm{~mm}$.

Distance determination. The results showed that: there was no statistically significant difference in the distance from LSC 


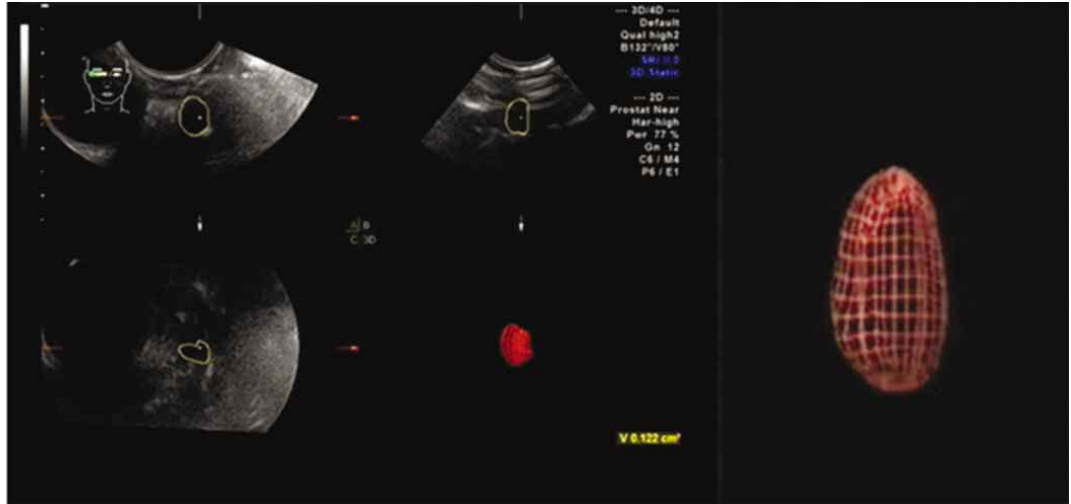

Fig. 1. Lacrimal sac artificially traced and amplified by VOCAL technology.

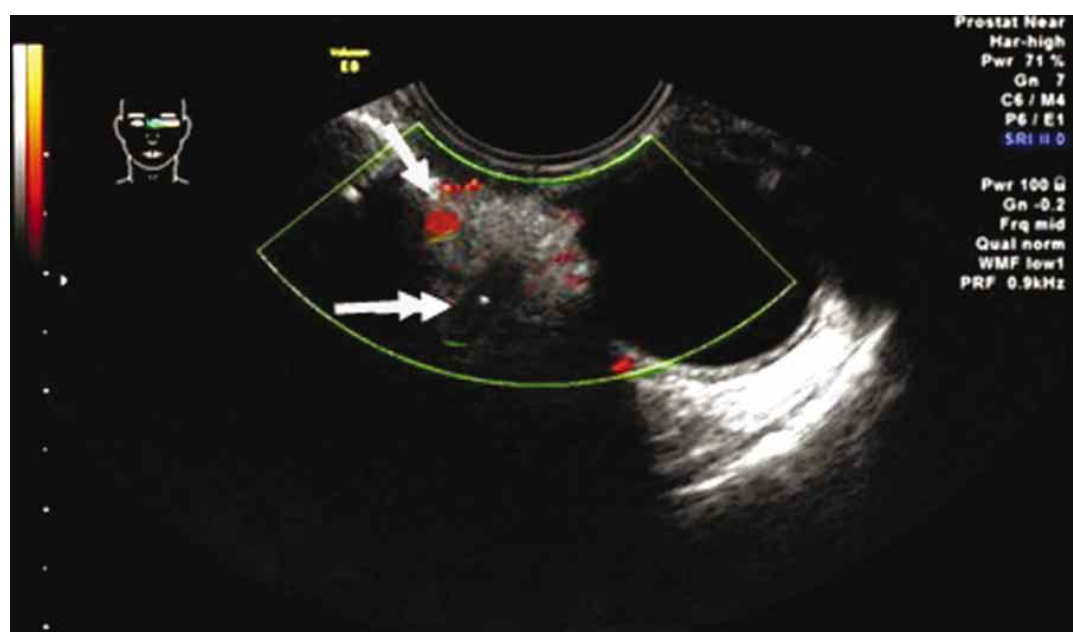

Fig. 2. Angular artery lacrimal sac.

Table I. Vertical diameter, anteroposterior diameter and trans diameter of LSC (mm).

\begin{tabular}{lccc}
\hline & Vertical diameter & Anteroposterior diameter & Trans diameter \\
\hline Male & $13.5 \pm 2.0$ & $6.2 \pm 1.1$ & $5.0 \pm 0.9$ \\
Female & $13.1 \pm 2.2$ & $5.8 \pm 1.0$ & $4.8 \pm 0.8$
\end{tabular}

Note: $\mathrm{t} 1=1.63, \mathrm{t} 2=1.45, \mathrm{t} 3=1.41$ : there was no statistically significant difference in the vertical diameter, anteroposterior diameter and trans diameter of LSC between the different sexs.

Table II. Distance determination of LSC (top, bottom) to the skin and medial canthus (mm).

LSC top to skin LSC bottom to skin LSC top to medial LSC bottom to

\begin{tabular}{lcccc} 
& & & canthus & medial canthus \\
Male & $6.5 \pm 0.12$ & $6.8 \pm 0.11$ & $5.9 \pm 0.11$ & $8.8 \pm 0.12$ \\
Female & $6.1 \pm 0.11$ & $6.2 \pm 0.12$ & $5.7 \pm 0.12$ & $8.6 \pm 0.10$ \\
\hline
\end{tabular}

Note: $\mathrm{t} 1=1.30, \mathrm{t} 2=1.45$ : there was no statistically significant difference in the distance from LSC (top, bottom) to the skin between the different sexs; $\mathrm{t} 3=1.56, \mathrm{t} 4=1.63$ : there was no statistically significant difference in the distance from LSC (top, bottom) to the medial canthus between the different sexs.

Table III. Distance determination of the angular artery to the skin and medial canthus (mm).

\begin{tabular}{ccc}
\hline & Angular artery to skin & Angular artery to medial canthus \\
\hline Male & $7.8 \pm 0.08$ & $8.0 \pm 0.04$ \\
Female & $7.6 \pm 0.09$ & $7.9 \pm 0.06$ \\
\hline
\end{tabular}

Note $: \mathrm{t} 1=1.38, \mathrm{t} 2=1.34$ : there was no statistically significant difference in the distance from the angular artery to the skin and medial canthus between the different sexs. (top, bottom) to the skin and medial canthus between the different sexes; there was no statistically significant difference in the distance from the angular artery to the skin and medial canthus between the different sexs (Tables II and III).

\section{DISCUSSION}

The lacrimal sac locates behind the medial canthal ligaments, and within the fossa of lacrimal sac which is composed by the lacrimal bone and process of frontalis maxilla, its upper portion is the caecum, and the lower portion is connected with the nasolacrimal duct, the ideal imaging examination should clearly display the in vivo lacrimal sac and its surrounding tissues, at the same time, it should be economic, convenient, non-invasive and reproducible. The X-ray dacryocystography with iodized oil could well develop the size and shape of lacrimal sac, but because the injection of contrast agent adds certain factitious pressure, it would exhibit less sensitivity towards the functional lacrimal duct obstructionand mild lacrimal duct stenosis, and because of the overlapped organs, it would be difficult to display the lacrimal duct structure accurately and clearly (Peter et al., 2009). In recent years, the newly emerged lacrimal CT 3D reconstruction, based on the contrast agent injection (iodized oil) into LSC, could perform the tomoscan, and it could penetrate the surrounding bony substances, and display LSC, but because its premise is also based on the injection of contrast agent into LSC, so the displayed LSC is not its natural size (Limongi et al., 2012; Yu et al., 2013). the ultrasonography has the characteristics of economy, convenience, noninvasion and reproducibility (Pavlidis et al., 2005; Bojakowski et al., 2013; Beltrán et al., 2015), while the commonly used ophthalmic ultrasound (10 MHz) 
is a 2D ultrasound (Stupp et al., 2004; Tan et al., 2011), which could not exhibit the 3D structure of LSC, and it could also not display the situations of surrounding blood supply.

The results of this study showed that the approximate shape of lacrimal sac was the oval cystic structure, with its vertical diameter as the longest diameter, while the anteroposterior diameter was the shortest, and rich blood flow signals could be seen above the nose (angular artery). The test results were consistent with those of Tan et al. (1988), who used 7.5 MHz to scan LSC of normal adults, the results of A type and B type $2 \mathrm{D}$ ultrasonic examination towards the LSC size, shape and relationships with the surrounding tissues were consistent, but this literature did not exhibit the contents of blood flow signals. In this paper, the ultrasonic 3D highfrequency and frequency-conversing volumetric probe were used, and the study found that: this technology could not only retain the advantages of 2D imaging, but also sterically display the outline of LSC, as well as the relationships of surrounding blood supply and tissues, and measure the anatomical imaging data of lacrimal sac and angular artery.

LSC would exhibit the low level echo inside the ultrasound imaging, while the wall would exhibit the high level echo. The hypoechoic area would become larger from the distal segment to the middle segment and the proximal segment, then become smaller, which supports the fact that LSC is an elongated oval- shaped structure, and the nasal side of LSC exhibits the rich blood flow signals, which is the angular artery ( Figs. 1 and 2 ).

The results of this study showed that, under the eyeclosed state, the vertical cavity diameter: $13.3 \pm 2.2 \mathrm{~mm}$; the anteroposterior diameter: $6.0 \pm 1.1 \mathrm{~mm}$; the trans diameter:
$4.9 \pm 0.9 \mathrm{~mm}$, close to the report of Liu et al. (2009), that LSC of Chinese population was about $12 \mathrm{~mm}$, with anterior posterior width as $4-7 \mathrm{~mm}$, and right-left width as $2-3 \mathrm{~mm}$; the distance from LSC top to the medial canthus: $5.8 \pm 0.11 \mathrm{~mm}$, the distance from LSC bottom to the medial canthus $8.7 \pm 0.11$ $\mathrm{mm}$, slightly higher than Wormald et al. (2000), who measured the above distances as $5.3 \mathrm{~mm}$ and $7.7 \mathrm{~mm}$, the reason might lie in the different inspection methods, patients' own situations, nationalities and sample sizes, etc.; the vertical distance from LSC top to the skin: $6.3 \pm 0.12 \mathrm{~mm}$, and the vertical distance from LSC bottom to the skin: $6.5 \pm 0.11 \mathrm{~mm}$, these data had not been reported domestically and abroad, and also needed the further confirmation from the physical anatomy. Although the experiment completed the measurements of LSC volume and different diameters, the imaging of partial LSC was not good due to the surrounding bony substances and the individual situations, thus the measurement results existed some errors, so the ultrasonic 3D examination technology still needed the further improvement.

The diameter of angular artery was about $0.7 \pm 0.3 \mathrm{~mm}$, which was consistent with Lee (Li et al., 2000) [0.8 $\pm 0.2(0.5$ $\sim 1.0$ ) $\mathrm{mm}$ ]; and it could be seen from Table III that the distance from the angular artery to the medial canthus: $7.8 \pm 0.05 \mathrm{~mm}$; and that from the angular artery to the skin: $7.7 \pm 0.08 \mathrm{~mm}$. This paper reported the different distances within LSC, thus it could provide the reference towards the clinical lacrimal surgery.

In short, U3DR could clearly exhibit the in vivo adult lacrimal sac and angular artery, the accumulated imaging anatomical parameters could provide the instructive meanings towards the clinical diagnosis and treatment of lacrimal diseases.

TAO, H.; LIU, X.; MEI, X.; HAN, C.; WANG, P. \& BAI, F. Reconstrucción 3D con ultrasonido y mediciones del saco lagrimal en una población China de adultos normales. Int. J. Morphol., 34(4):1357-1361, 2016.

RESUMEN: El objetivo de este estudio consistió en aplicar el método de reconstrucción 3D de ultrasonidos para medir los datos de las imágenes anatómicas del saco lagrimal en una población china adulta normal, proporcionando imágenes con base anatómica para el diagnóstico clínico y el tratamiento de las enfermedades de los conductos lagrimales. La muestra consistió en 80 voluntarios sin enfermedades de los conductos lagrimales. Se utilizó el aparato de ultrasonido GE Voluson E8, con una sonda intracavitaria ginecológica (frecuencia: $5 \sim 12 \mathrm{MHz}$ ) para realizar el examen y la medición. Cada dato se repitió tres veces para obtener el valor medio. De los 80 ojos, los sacos lagrimales de 74 ojos mostraron una imagen clara, siendo la tasa de formación de imágenes del 92,5\%. Se realizaron mediciones: diámetro vertical de la cavidad del saco lagrimal (LSC): 13,3 $\pm 2,2 \mathrm{~mm}$; diámetro anteroposterior: $6,0 \pm 1,1 \mathrm{~mm}$; diámetro transversal: 4,9 $\pm 0,9 \mathrm{~mm}$; distancia vertical desde la porción superior de la cavidad del saco lagrimal hasta la superficie de la piel: $6,3 \pm$ $0,12 \mathrm{~mm}$, distancia vertical desde el fondo de la cavidad del saco lagrimal hasta la superficie de la piel: $6,5 \pm 0,11 \mathrm{~mm}$; distancia desde la arteria angular al canto medial: 7,8 $\pm 0,05 \mathrm{~mm}$; distancia vertical desde la arteria angular a la superficie de la piel: 7,7 $\pm 0,08 \mathrm{~mm}$. El saco lagrimal y la arteria angular en los adultos se podría demostrar claramente en la reconstrucción 3D con ultrasonido. Los parámetros anatómicos acumulados podrían ser de significativo valor para un certero diagnóstico clínico y tratamiento de enfermedades de los sacos lagrimales.

PALABRAS CLAVE: Saco lagrimal; Reconstrucción 3D de imágenes por ultrasonido; Anatomía imagenológica. 


\section{REFERENCES}

Agrawal, S.; Gupta, S. K.; Singh, V. \& Agrawal, S. A novel technique to recanalize the nasolacrimal duct with endodiathermy bipolar probe. Indian J. Ophthalmol., 61(12):718-21, 2013.

Beltrán, L. M.; García-Casasola, G. \& Members of the Group of Clinical Ultrasound of the Spanish Society of Internal Medicine. Ultrasonography managed by internists: the stethoscope of 21st century? Rev. Clin. Esp. (Barc.), 214(3):155-60, 2014.

Berlucchi, M.; Staurenghi, G.; Rossi Brunori, P.; Tomenzoli, D. \& Nicolai, P. Transnasal endoscopic dacryocystorhinostomy for the treatment of lacrimal pathway stenoses in pediatric patients. Int. J. Pediatr. Otorhinolaryngol., 67(10):1069-74, 2003.

Bojakowski, K.; Góra, R.; Szewczyk, D. \& Andziak, P. Ultrasoundguided angioplasty of dialysis fistula - technique description. Pol. J. Radiol., 78(4):56-61, 2013.

Bojikian, K. D.; de Moura, C. R.; Tavares, I. M.; Leite, M. T. \& Moron, A. F. Fetal ocular measurements by three-dimensional ultrasound. J. A. A. P. O. S., 17(3):276-81, 2013.

Byun, J. M.; Kim, Y. N.; Jeong, D. H.; Kim, K. T.; Sung, M. S. \& Lee, K. B. Three-dimensional transvaginal ultrasonography for locally advanced cervical cancer. Int. J. Gynecol. Cancer, 23(8):1459-64, 2013.

Hodgson, N.; Bratton, E.; Whipple, K.; Priel, A.; Oh, S. R.; Fante, R. G.; Kikkawa, D. O. \& Korn, B. S. Outcomes of endonasal dacryocystorhinostomy without mucosal flap preservation. Ophthal. Plast. Reconstr. Surg., 30(1):24-7, 2014.

Lee, M. J.; Khwarg, S. I.; Choung, H. K. \& Kim, N. Associated factors of functional failure of external dacryocystorhinostomy. Can. J. Ophthalmol., 49(1):40-4, 2014.

Lembet, A.; Bodur, H.; Selam, B. \& Ergin, T. Prenatal two- and threedimensional sonographic diagnosis of dacryocystocele. Prenat. Diagn., 28(6):554-5, 2008.

Li, W.; Zeng, F.; Zhan, Y. \& Xu, M. Applied anatomy of the transposition of musculocutaneous flap of quadrate muscle of upper lip for repairing skin defect in the middle region of face. Chin. J. Clin. Anat., 2000(1):37-8, 2000.

Limongi, R. M.; Magacho, L.; Matayoshi, S.; Carneiro, H. M. \& Avila, M. Computed tomographic dacryocystography in children undergoing balloon dacryoplasty. J. A. A. P. O. S., 16(5):464-7, 2012.

Liu, J. Q. \& Li, F. M. Practical Ophthalmology. Beijing, People's Hygiene Publishing House, 2009.

Pavlidis, M.; Stupp, T.; Grenzebach, U.; Busse, H. \& Thanos, S. Ultrasonic visualization of the effect of blinking on the lacrimal pump mechanism. Graefes Arch. Clin. Exp. Ophthalmol., 243(3):228-34, 2005.

Peter, N. M. \& Pearson, A. R. Comparison of dacryocystography and lacrimal scintigraphy in the investigation of epiphora in patients with patent but nonfunctioning lacrimal systems. Ophthal. Plast. Reconstr. Surg., 25(3):201-5, 2009.

Prager, R. W.; Ijaz, U. Z.; Gee, A. H. \& Treece, G. M. Three-dimensional ultrasound imaging. Proc. Inst. Mech. Eng. H, 224(2):193223, 2010.

Stupp, T.; Pavlidis, M.; Busse, H. \& Thanos, S. Presurgical and postsurgical ultrasound assessment of lacrimal drainage dysfunction. Am. J. Ophthalmol., 138(5):764-71, 2004.

Tan, S.; Özcan, A. S.; Akçay, E. \& Süngü, N. Sonographic appearance of primary lacrimal sac lymphoma. J. Ultrasound Med., 30(4):574-5, 2011.

Tang, X. C. \& Wei, H. R. Applications of ultrasonic diagnosis on lacrimal duct disease. Chin. J. Pract. Ophthalmol., 4:419-21, 1988.

Tao, H.; Ma, Z. Z.; Wu, H. Y.; Wang, P. \& Han, C. Anatomic study of the lacrimal fossa and lacrimal pathway for bypass surgery with autogenous tissue grafting. Indian J. Ophthalmol., 62(4):41923, 2014 .

Tao, H.; Wang, P.; Han, C.; Zhang, J.; Bai, F. \& He, Z. Y. One-stitch anastomosis through the skin with bicanalicular intubation: a modified approach for repair of bicanalicular laceration. Int. J. Ophthalmol., 6(5):656-8, 2013.

Wormald, P. J.; Kew, J. \& Van Hasselt, A. Intranasal anatomy of the nasolacrimal sac in endoscopic dacryocystorhinostomy. Otolaryngol. Head Neck Surg., 123(3):307-10, 2000.

Yu, G.; Zhang, C. Y.; Cui, Y. H.; Fan, Y. W.; Cao, W. H.; Lin, Q.; Qi, Y.; Cui, J.; Hu, M.; Liu, W. \& Wu, Q. Application value of computed tomography dacryocystography in children lacrimal diseases. Zhonghua Yan Ke Za Zhi, 49(8):706-10, 2013.

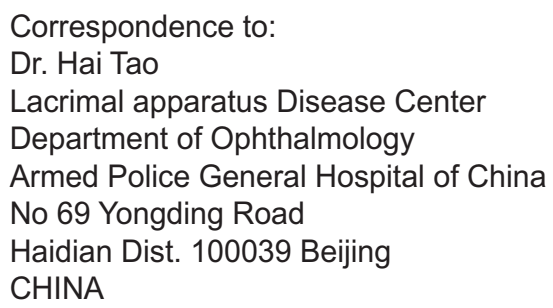

\section{E-Mail: haitaodoc@126.com}

Received: 15-10-2015

Accepted: 03-08-2016 